\title{
ALEXITHYMIA AS PREDICTOR OF TREATMENT OUTCOME IN PATIENTS WITH OBSESSIVE-COMPULSIVE DISORDER : A PROSPECTIVE STUDY.
}

Author: Sung-Hyuk Kang a,b, Chun II Park a,b, Heeyeon Kim a,b, Jee In Kang a,b, , Se Joo Kim a,b,

a Department of psychiatry, Yonsei University College of Medicine, Seoul, South Korea

b Institute of Behavioral Science in Medicine, Yonsei University College of Medicine, Seoul, South Korea

\section{Introduction}

Obsessive-compulsive disorder(OCD) is a mental disorder consisting persistent and recurrent thoughts, images, or impulses, and compulsions defined as repetitive and irrational behaviors or mental acts. OCD is often regarded as being difficult to treat, at least $10 \%$ of patients are refractory to psychopharmacological treatment.

People with OCD usually use isolation of affect as psychodynamic defense to fend off inner aggression and control intolerable emotions. Alexithymia is defined as difficulties in identifying and describing feelings, deficits in the regulation of emotions. Alexithymia may play a critical role in the production and maintenance of obsessive-compulsive symptoms, and probably prognosis of disorder. Alexithymia has been shown to worsen treatment outcome in various psychiatric illness such as panic disorder, posttraumatic stress disorder, and eating disorders.

The objective of this study with a prospective cohort design was to investigate impact of alexithymia and clinical risk factors on treatment response at 4-month follow-up after serotonin reuptake inhibitor (SRI) medication in drug-free patients with OCD.

\section{Methods}

\section{Participants}

A total of 100 patients with OCD were recruited for this study from the OCD clinic of Severance Hospital. All participants were drugfree status when they were included and had not been treated with pharmacotherapy for at least 8 weeks.

\section{Assessments}

Obsessive and compulsive symptom severity were assessed with the Yale-Brown Obsessive Compulsive Scale(Y-BOCS). Alexithymia was assessed using the Toronto Alexithymia Scale, containing the following factors: difficulty identifying feelings, difficulty describing feelings, and externally oriented thinking Treatment responders were determined by significant reduction $(\geq 35 \%)$ of the Y-BOCS scores after 4 months of SRI treatment.

\section{Statistical Analysis}

Independent T-test and chi-square test was applied to determine which variables were correlated with treatment response. Multivariate analysis of covariance (MANCOVA) was used to compare alexithymia level between treatment responders and nonresponders controlling for confounding variables which were expected to affect treatment response of OCD.

\section{Results}

Treatment responders scored significantly lower for alexithymia such as difficulty describing feeling and identifying feeling compared to non-responders, and not significantly different for externally-oriented thinking.
TABLE 1 Demographic and clinical characteristic of OCD patients with or without treatment response

Treatment response

$\mathrm{N}(\%)$ or Mean (SD)

$\begin{array}{ccccc}\text { Total } & \text { Responder } & \begin{array}{c}\text { Non- } \\ \text { responder }\end{array} & t / x^{2} & p \\ (\mathrm{~N}=100) & (\mathrm{N}=44) & (\mathrm{N}=56) & & \end{array}$

Gender

$0.021 \quad 0.884$

$\begin{array}{llll}\text { Female } & 44(44.0) & 19(19.0) & 25(25.0) \\ \text { Male } & 56(56.0) & 25(25.0) & 31(31.0)\end{array}$

Age

$28.93(10.27) 28.95(10.43) 28.91(10.23)$

Mariatal

status

Yes

No

Education

year

$19(19.0)$

$10(10.0)$

Onset age
Duration of

34(34.0)

illness

$13.98(2.24) \quad 14.02(2.17)$

$13.95(2.31) \quad-0.169 \quad 0.866$

Depression

$9.45(8.98) 21.11(10.29)$

$18.14(7.65)-1.655 \quad 0.101$

Yes

$9.48(8.52)$

$7.84(6.00)$

$10.77(9.94)$

$1.821 \quad 0.065$

$4.813 \quad 0.028$

No

Y-BOCS

$32(32.0 \%)$

9(9.0)

23(23.0)

$68(68.0 \%)$

$35(35.0)$

33(33.0)

$27.96(4.96) \quad 28.98(4.61)$

$27.16(5.11) \quad-1.840$

0.069

TABLE 2 Multivariate analysis comparing alexithymia subscales score for treatment response after controlling for age, sex, comorbid depression

\begin{tabular}{lccccc}
\hline & \multicolumn{2}{c}{ Total $(\mathrm{N}=100)^{\mathrm{a}}$} & & & \\
\cline { 2 - 4 } & $\begin{array}{c}\text { Responder } \\
(\mathrm{N}=44)\end{array}$ & $\begin{array}{c}\text { Non-responder } \\
(\mathrm{N}=56)\end{array}$ & $\mathrm{F}$ & $\mathrm{p}$ & $\eta_{\mathrm{p}}{ }^{2}$ \\
\hline TAS & $48.68 \pm 12.38$ & $55.32 \pm 10.88$ & 5.16 & 0.025 & 0.052 \\
total & $13.00 \pm 4.81$ & $15.38 \pm 3.95$ & 5.04 & 0.027 & 0.050 \\
DDF & $15.95 \pm 6.16$ & $19.54 \pm 5.94$ & 5.42 & 0.022 & 0.054 \\
DIF & $19.73 \pm 3.96$ & $20.41 \pm 3.73$ & 0.30 & 0.583 & 0.003 \\
EOR & &
\end{tabular}

a responder - Wilks $\lambda=0.94, F_{(3,93)}=2.14, p=0.101$, age - Wilks $\lambda=0.87, F_{(3,}$, 93) $=4.62, p=0.005$, sex - Wilks $\lambda=0.93, F_{(3,93)}=2.21, p=0.092$, comorbid depression - Wilks $\lambda=0.91, F_{(3,93)}=3.40, p=0.021$

Abbreviations:

TAS $=$ Toronto alexithymia scale

$\mathrm{DDF}=\mathrm{TAS}$, Difficulty describing feelings subscale

DIF $=$ TAS, Difficulty identifying feeling subscale

$E O R=$ TAS, Externally-oriented thinking subscale

\section{Conclusion}

The present findings indicate that alexithymia, especially the trait that is difficult to describe and identify inner feelings, predicts unfavorable treatment outcome in patients with $O C D$, regardless of initial clinical severity of disorder. It may be useful for clinicians to be aware that alexithymic patients are resistant to pharmacotherapy, therefore various treatment options would be needed.

This work was supported by the National Research Foundation of Korea (NRF) grant funded by the Korea government (NRF-2018R1A2B2007714) 